\title{
Porosity Formation and Evolution of the Deeply Buried Lower Triassic Feixianguan Formation, Puguang Gas Field, NE Sichuan Basin, China
}

\author{
Xuefeng Zhang ${ }^{1}$, Tonglou Guo ${ }^{2}$, Bo Liu ${ }^{1}$, Xiaoyue $\mathrm{Fu}^{2}$, Shuanglin $\mathrm{Wu}^{1}$ \\ ${ }^{1}$ Institute of Oil \& Gas; School of Earth and Space Sciences, Peking University, Beijing, China \\ ${ }^{2}$ Southern Exploration and Development Company, SINOPEC, Chengdu, China \\ Email: zhangxf@pku.edu.cn
}

Received March 13, 2013; revised April 20, 2013; accepted April 28, 2013

Copyright (C) 2013 Xuefeng Zhang et al. This is an open access article distributed under the Creative Commons Attribution License, which permits unrestricted use, distribution, and reproduction in any medium, provided the original work is properly cited.

\begin{abstract}
The deeply buried shoal dolomite reservoirs of the Lower Triassic Feixianguan Formation, giant Puguang Gas Field, NE Sichuan Basin, are exceptionally porous. The influences of diageneses on pore evolution are studied. Through petrologic investigation, diagenetic phases are divided into four stages, i.e., near-surface, pre-oil window, oil window, and gas window. The Adobe Photoshop system is used to quantify the rock texture components, porosity constitutions and the influences of diageneses on reservoir porosity. Porosity evolution curves are quantitatively recovered. The Feixianguan reservoir porosities are mainly created by early meteoric dissolution, dolomitization, and organic acids dissolution. Dissolution during deep burial is insignificant. Pores are formed in near-surface and pre-oil window stages and effectively preserved till present. This result may be of great significance to the further exploration of deeply buried carbonate reservoirs not only in NE Sichuan Basin, but also around the world.
\end{abstract}

Keywords: Porosity Evolution; Diagenesis; Lower Triassic Feixianguan Formation; Puguang Gas Field; Sichuan Basin

\section{Introduction}

Ehrenberg et al. (2009) [1] showed a trend of carbonate porosity decreasing with burial depth and age based on Statoil's global reservoir database. However, a notable exception to that is the Triassic [1]. One of the possible reasons for this abnormity, according to the authors, is the limited data. Thirty four percent of the overall 284 Triassic carbonate reservoirs are from China, mainly the Jialingjiang Formation at a depth of $<2.3 \mathrm{~km}$, with porosities $<5.1 \%$ [1]. However, the recently discovered Puguang Gas Field [2,3] is not included in the database. Data from this new gas-field may help evaluate the Triassic abnormity.

The giant Puguang Gas Field discovered in 2003 is the largest gas field found in marine carbonates within China with an estimated gas reserve of $350 \times 10^{9} \mathrm{~m}^{3}(1236 \mathrm{BCF})$ [2]. The oolitic dolostone of the Lower Triassic Feixianguan Formation is one of the major reservoir rock types with the maximum porosity up to $\sim 30 \%$. This reservoir is exceptionally porous considering the deep burial depth (4800 - $5500 \mathrm{~m}$ ), high temperature, thermally overmature and multiple-stages of tectonic deformation [2-4]. How these pores formed and evolved are the major concerns of exploration as well as of this research.

\section{Geological Setting}

The Puguang Gas Field is located on the Shuangshimiao-Puguang structural belt in the NE Sichuan Basin, Southwest China (Figure 1; [2]). The Sichuan Basin has a complex sedimentary and tectonic history due to several important tectonic episodes or "movements" since the Late Proterozoic [2-4]. As a result of tectonic evolution and eustacy, strata within and below the middle Triassic Leikoupo Formation $\left(\mathrm{T}_{2} \mathrm{l}\right)$ are generally dominated by carbonate lithologies. Clastic rocks were deposited during and after the Upper Triassic Xujiahe period. The Upper Permian Changxing Formation and the Lower Triassic Feixianguan Formation are two major reservoir intervals of the Puguang Gas Field and many other gas-fields in the eastern Sichuan Basin [2].

The Feixianguan Formation is subdivided into four members, namely the first to the fourth member from base to top, of which the effective reservoirs are in the first to the third members. Sediments in the first and 


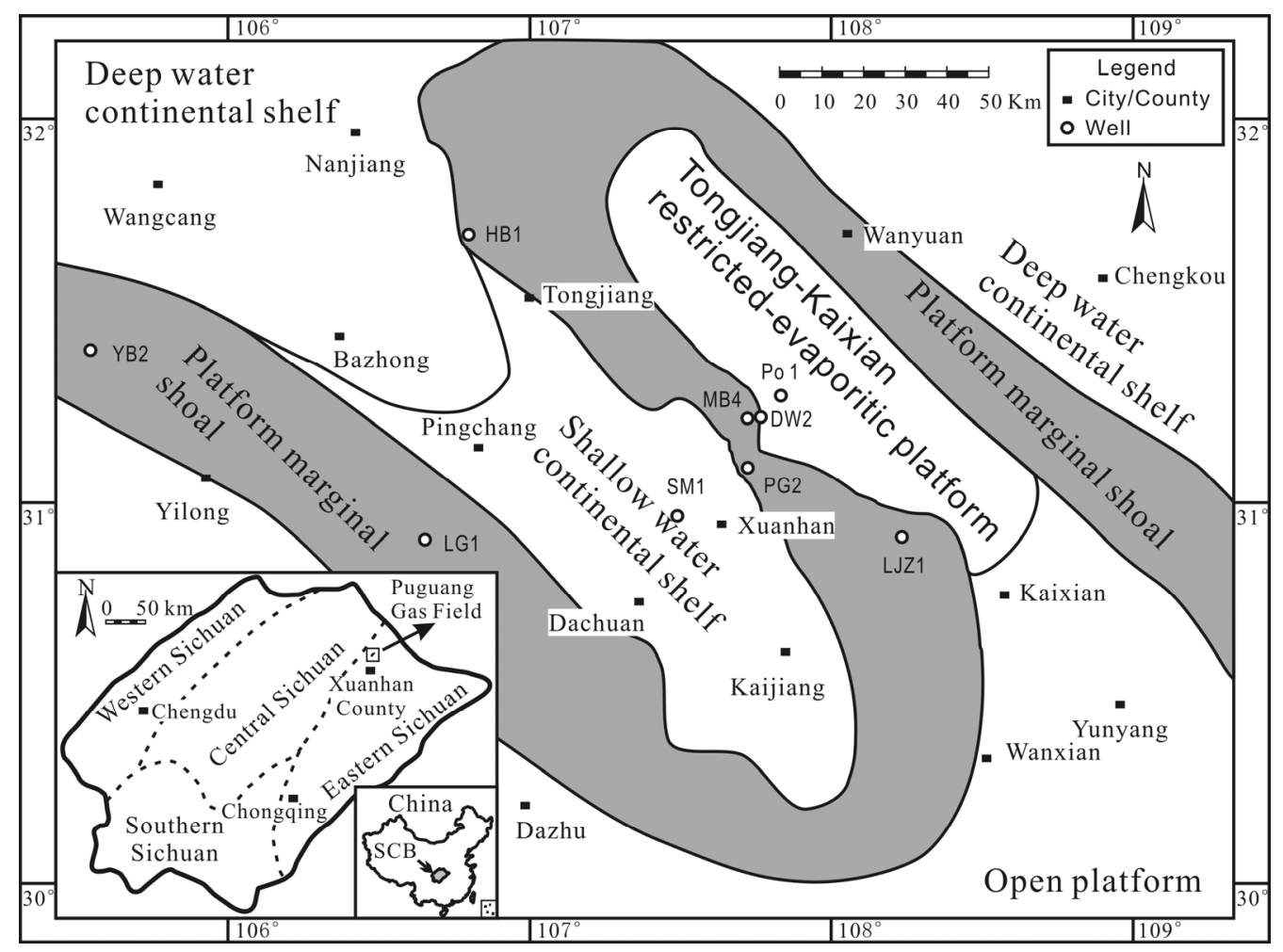

Figure 1. Geological map showing the locations of the Sichuan Basin (SCB), the Puguang Gas Field, drilling wells, and sedimentary facies during the Early Triassic Feixianguan Period as well.

second members are dominated by oolites interbeded by mudstone carbonates deposited in platform-margin shoal; while the third to the fourth units are mainly micritic to fine dolomites and micritic limestones with interlayered anhydrites in the fourth member [2]. Notably, evaporates of different thicknesses (several to $\sim 100 \mathrm{~m}$ thick) developed in the interior of the first to the second member in the Tongjiang-Kaixian area, which indicates an evaporatic platform was developed adjacent to the oolitic shoal (Figure 1). Dolomites are heterogeneous in thickness, which are dominantly distributed around the Puguang area. In the Well PG2, oolitic dolomite and crystalline dolomite comprise the main reservoir section of about $400 \mathrm{~m}$ (1312 ft.). Above the Feixianguan Formation, the Jialingjiang Formation and the Leikoupo Formation are deposited as thick and basinwide anhydrite, halite, and gypsiferous dolomite, which provide regional seals to the Puguang and other gas-fields [2].

The Feixianguan carbonates reached maximum burial depth of about $7000 \mathrm{~m}(22966 \mathrm{ft}$.) at $\sim 120$ Ma before being uplifted to the present depth of about $4800-5700$ $\mathrm{m}(15748$ - $18700 \mathrm{ft}$.) and the calculated present-day thermal maturity is approximately between $2.0 \%$ and $2.5 \% \mathrm{R}_{\mathrm{o}}$ [4]. Although deeply buried, the Feixianguan reservoir exhibits high porosity up to $29 \%$ and high permeability $9664 \mathrm{md}$.

Natural gas produced from the Feixianguan reservoir in the Puguang field is typically dry, with approximately $80 \%$ methane, less than $0.5 \% \mathrm{C}_{2+}$ alkanes, and is rich in $\mathrm{H}_{2} \mathrm{~S}(5.1 \%-62.2 \%, 19.7 \%$ in average $)$ and $\mathrm{CO}_{2}(2.6 \%$ $35.6 \%, 11.9 \%$ in average) $[3,4]$. The gas geochemistry and the presence of extensive pyrobitumens in the reservoir provide clear evidence for an early oil charge and formation of a paleo-oil reservoir during the TriassicJurassic late Indosinian-early Yanshanian orogenies. During the Late Jurassic-Cretaceous Yanshanian Orogeny, oil in the paleo-trap was cracked into thermal gas under higher temperatures.

\section{Methods}

Twenty eight cores and four outcrops were investigated. Six hundred and thirty samples were taken from the core and the outcrop material perpendicular to bedding surfaces at $0.2-2.0 \mathrm{~m}$ intervals. Three hundred and sixty polished thin sections were prepared after the samples were impregnated with purple epoxy for easy porosity identification. The thin sections were stained with Alizarin Red-S to identify calcite and dolomite.

Optical investigation was conducted conventionally under microscope. On principles of superposition and crosscutting, relative timing of diagenetic phases was determined.

Rock texture components and porosities are quantified by Adobe Photoshop Analysis [5]. This method is based 
on microscopic images taken from stained and impregnated thin sections. One can easily and precisely select an area of interest in those images with the selecting tools of Adobe Photoshop. In other words, grains, cements, matrix and porosities of different types can be selected separately in carbonates. Then, the pixels of the selected zone can be read in the menu of Image-Histogram-Pixels. The ratio of the pixels of the selected zone to that of the whole image equals to the percent area of the selected component. Consequently, the rock texture components and porosities of different types can be quantitatively determined. Figure 2 gives an example of the application of the Adobe Photoshop Analysis method, which shows good reproducibility of the results. In fact, this method is comparable to the commonly used methods such as estimating through naked eyes, visual comparison charts [6], point-counting [7,8], or usual image analysis [9], but more precise and easier to handle. In fact, the Adobe Photoshop Analysis method can also be used for modal analysis of granitic rocks [10] and quantitative assessment of sandstone porosity [11].

A total of 360 polished thin sections of both lime- stones and dolomites were imaged at least 6 times for each sample. Approximately 3000 images were analyzed by the Adobe Photoshop Analysis method. These data make the quantitative evaluation of porosity evolution of the reservoir rocks possible.

\section{Results}

Major diagenetic processes are identified as meteoric dissolution and cementation, early dolomitization, mechanical compaction, chemical compaction and related burial cementation, fracturing, hydrocarbon emplacement, oil cracking, pyrobitumen precipitation, gas accumulation, thermochemical sulfate reduction, and quartz crystallization during the late uplift of the Feixianguan reservoir.

Porosity types are classified as fabric-selective, partial-fabric-selective, and non-fabric selective using the classification criteria of Choquette and Pray (1970) [12].

The results show that most of the pores of the Feixianguan reservoir are fabric selective intragranular (including moldic porosity), intergranular or intercrystalline,
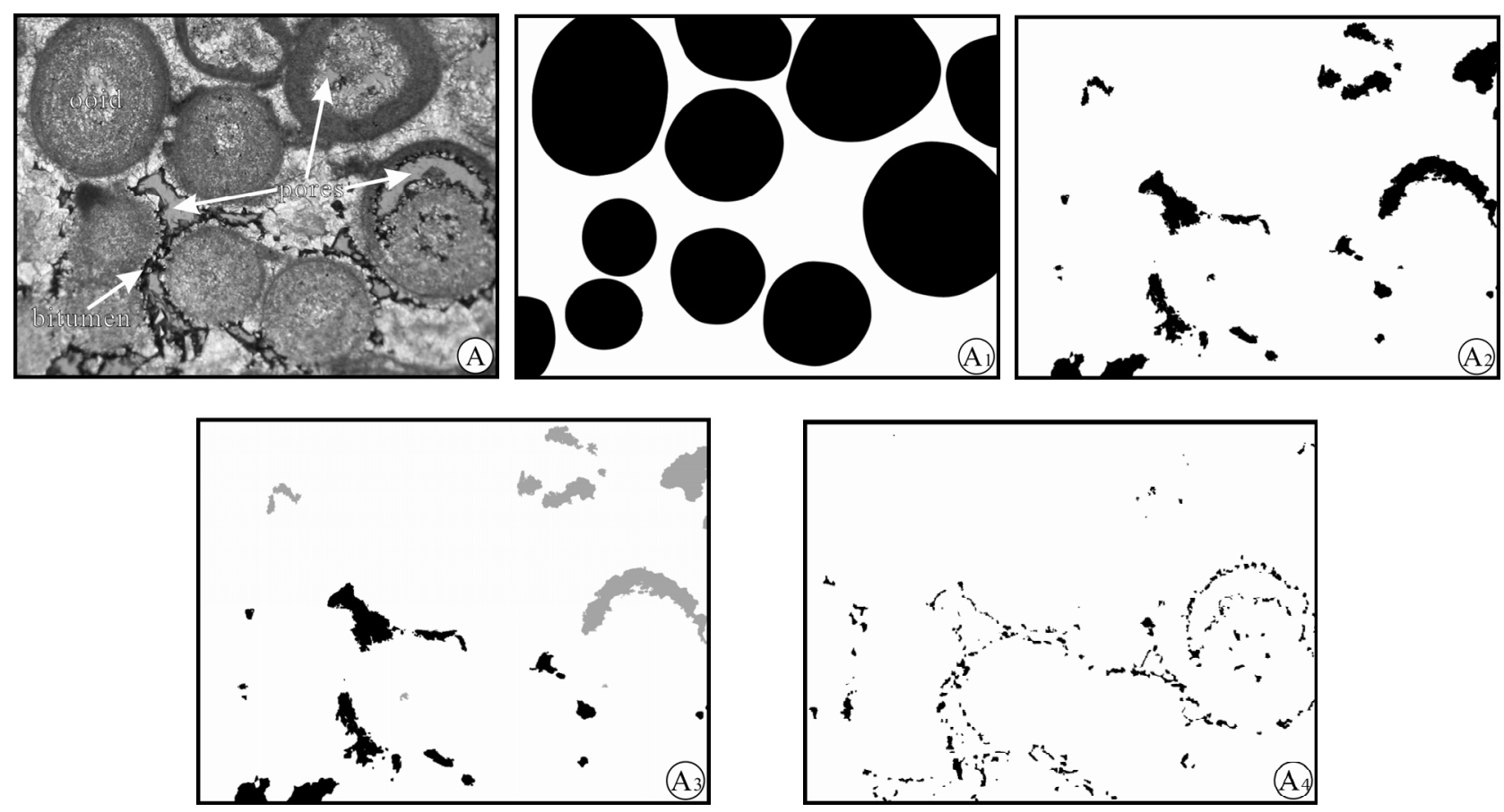

Figure 2. An example of the application of Adobe Photoshop Analysis. Figure 2A is the microscopic image of an oolitic dolomite which represents the typical rock type in the Lower Triassic Feixianguan Formation reservoir, Puguang Gas Field, NE Sichuan Basin. Pores within the sample are fabric-selective intragranular (WP) and intergranular (BP), in which bitumens precipitated. In Adobe Photoshop, ooids are identified and selected using the Pen Tool $\left(\mathrm{A}_{1}\right)$; effective porosities $\left(\mathrm{A}_{2}\right)$, WP (gray) and BP (black) porosities $\left(\mathrm{A}_{3}\right)$, and bitumens $\left(\mathrm{A}_{4}\right)$, respectively, using the Magic Wand Tool. Precise selections are made in Edit in Quick Mask Mode. Patience is needed when selecting bitumens because they are shapeless. Then the number of pixels of each selected zones are read; and the ratios of the pixels to that of the whole image are computed. Results show that the average ooid content is $57.69 \%$; total porosity $6.83 \%$; WP porosity $3.46 \%$; BP porosity $3.41 \%$; and bitumens $2.58 \%$, respectively. Dolomite cements can also be calculated as $100 \%-57.69 \%$ (grains) $-6.83 \%$ (porosity) $-2.58 \%($ bitumens) $=$ $32.90 \%$; and porosity before bitumen precipitation is $6.83 \%$ (present porosity) $+(2.58 \%$ (bitumens) $=9.41 \%$, which is considered the porosity when oil accumulated in this case. 
partly non-fabric selective vugs plus minor fractures, breccias and carverns. As shown in Figure 3, pores in Well PG2 are mainly intragranular and intercrystalline, partly intergranular. The reservoir quality is largely controlled by the abundance of intragranular and intercrystalline pores. While in Well MB4, pores are mainly intergranular, intercrystalline and vugs, among which intergranular and intercrystalline porosities determine the reservoir quality (Figure 3).

\section{Discussion}

\subsection{Diagenetic Processes}

The paragenetic sequence of the Feixianguan Formation was established using the criteria of Heydari (1997) [13]. Diagenetic phases are divided into four stages: 1) nearsurface (including marine and meteoric environment); 2) pre-oil window; 3) oil window; and 4) gas window (wet gas and dry gas). Each stage is related to a distinct phase
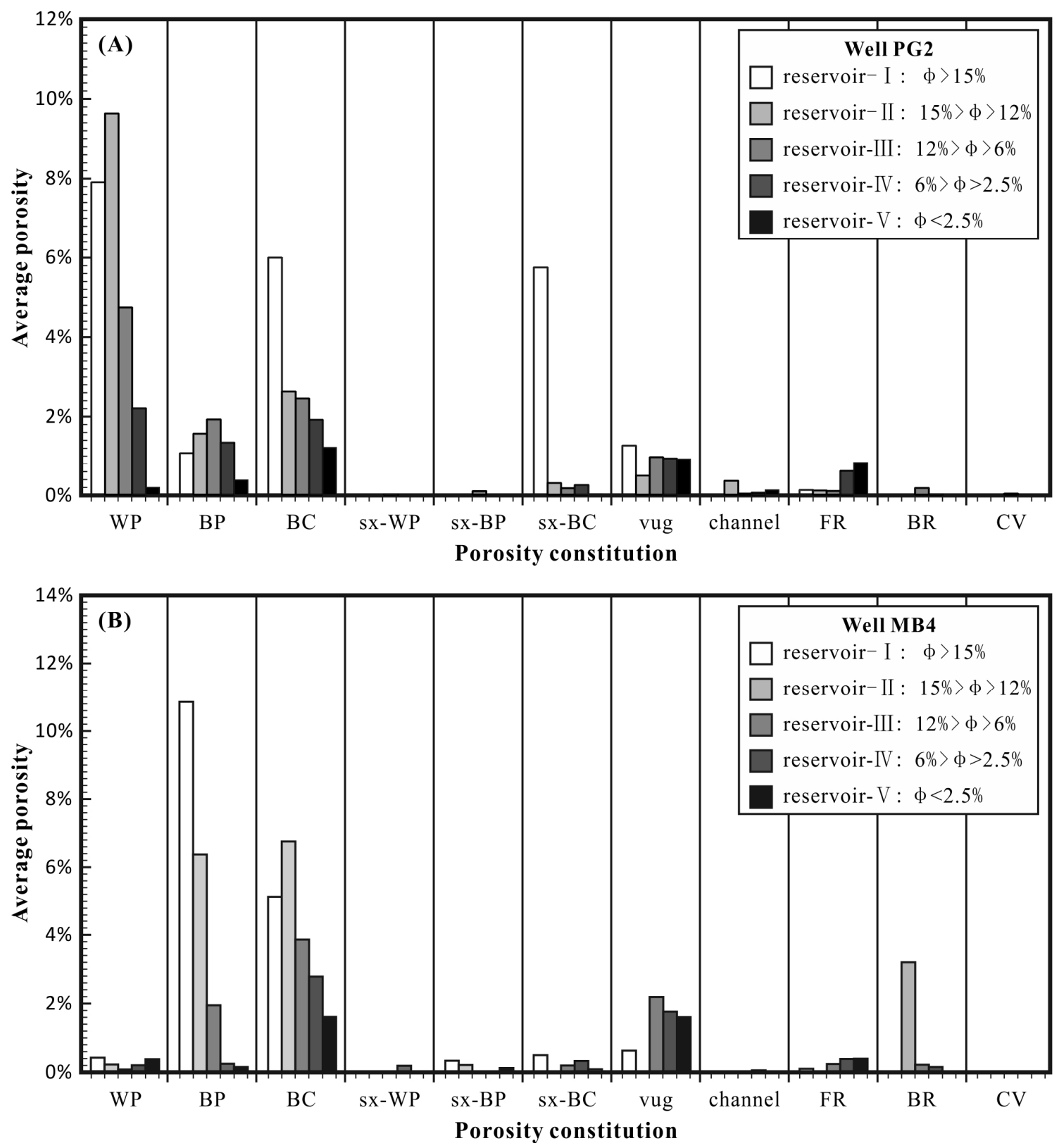

Figure 3. Porosity constitution of the Feixianguan reservoirs of the Well PG2 (A) and Well MB4 (B), Puguang Gas Field. Porosities are classified after Choquette and Pray (1970)[12] and averaged from a total of 140 and 80 samples, respectively. Porosity types on abscissa axis are: $\mathrm{WP}=$ intragranular pores, $\mathrm{BP}=$ intergranular pores, $\mathrm{BC}=$ intercrystalline pores, $\mathbf{s x}$-WP $=$ dissolution enlarged intragranular pores, $\mathbf{s x}-\mathrm{BP}=$ dissolution enlarged intergranular pores, $\mathbf{s x}-\mathrm{BC}=$ dissolution enlarged intercrystalline pores, vug, $\mathrm{FR}=$ fractures, $\mathrm{BR}=$ breccias, $\mathrm{CV}=$ caverns. It is clear that oomoldic/WP and $\mathrm{BC}$ pores are abundant in Well PG2, while vugs, BP and BC pores are dominant in Well MB4. 
of organic matter maturation and emplacement in the reservoir (Figures 4 and 5).

\section{Stage 1: Near Surface Diagenesis}

The Triassic marine water had high strontium concentration and was prone to precipitate aragonite, which is called the "aragonite sea" $[14,15]$. Consequently, the Triassic ooids in the NE Sichuan were likely aragonitic. During and slightly after deposition, the ooids were cemented and lithified in the marine environment. Generally, the marine cements developed mainly as micrite envelopes or isopachous crusts of aragonite on the surfaces of ooids (Figure 5(a)). The marine cementation had a negative influence on the reservoir pore evolution which could be quantified as the contents of the marine cements.

In the hypersaline environment, diageneses were characterized by penecontemporaneous dolomitization, as well as the related anhydrite nodularization or cementation (Figure 5(b)).

Due to the frequent sea-level fluctuations, the Feixianguan oolitic shoal was probably subaerially exposed after precipitation. And approximately at the end of the second period of Feixianguan, a regionally short-time exposure occurred. Unstable aragonitic ooid grains were leached or altered by neomorphism, and meteoric calcite cements precipitated (Figure 5(a)). Dissolution features were characterized by oomoldic or intragranular pores with geopetal structure (Figure 5(a)), dissolution-enlarged fractures, carvens and collapse breccia pores. However, gravitational and meniscus cements and microspar are hard to identify.
Porosity increase due to meteoric dissolution is identified by the pre-bitumen [16] oomoldic or intragranular pores with geopetal structure, dissolution-enlarged fractures, carvens, and collapse breccias. Nevertheless, meteoric cements are hard to identify because later dolomitization altered the rock textures. It is thought that meteoric diagenesis is relatively porosity neutral [6]. However, meteoric dissolution pores constitute a major part of the present reservoir space. And the meteoric cementation not only excluded pores, but also provided hard framework of the strata and effectively resisted compaction and porosity loss.

The near surface stage generally continued to the early shallow burial and ended before the onset of pressuresolution.

\section{Stage 2: Pre-Oil Window Diagenesis}

This stage represents the diagenetic realm during shallow burial before hydrocarbon emplacement. The principal diagenetic processes are dolomitization (Figure 5(c)), dolomite recrystallization or neomorphism (Figure 5(d)), physical compaction, chemical compaction and related burial cementation.

When and how the first and the second members of Feixianguan oolitic dolomites formed are still controversial. Major viewpoints include: 1) dolomitization by re fluxed brines (e.g., [17]) or 2) by meteoric/mixed water (e.g., [18]) in the early diagenetic stage, and 3) burial dolomitization by formation fluids in the late diagenetic stage (e.g., $[19,20])$. We found several pieces of evidence for judging the relative timing of dolomitization. Important considerations are:

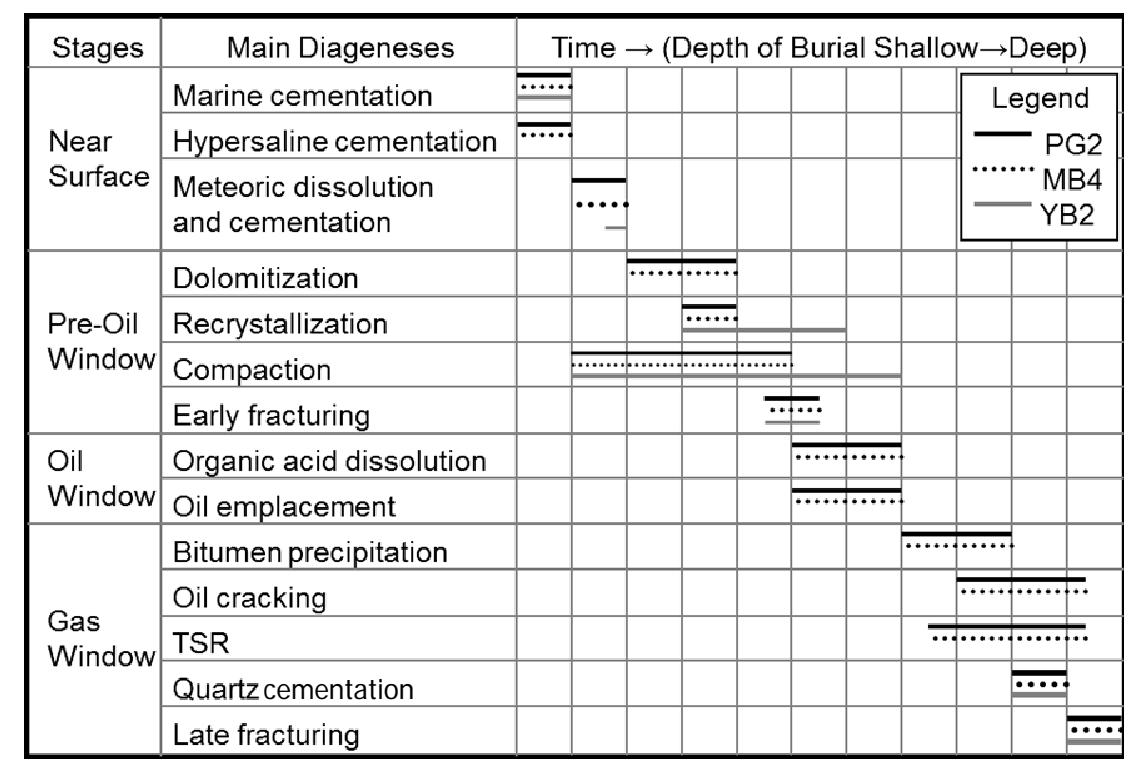

Figure 4. Paragenetic sequence of typical drilling wells at the Puguang (Well PG2), Maoba (Well MB4) and Yuanba area (Well YB2), NE Sichuan Basin, which summarizes major diagenetic events during near surface, pre-oil window, oil window, and gas window stages. Well locations are shown in Figure 1. The relative duration of diageneses is shown by the length and the intensity by the width of the line. 

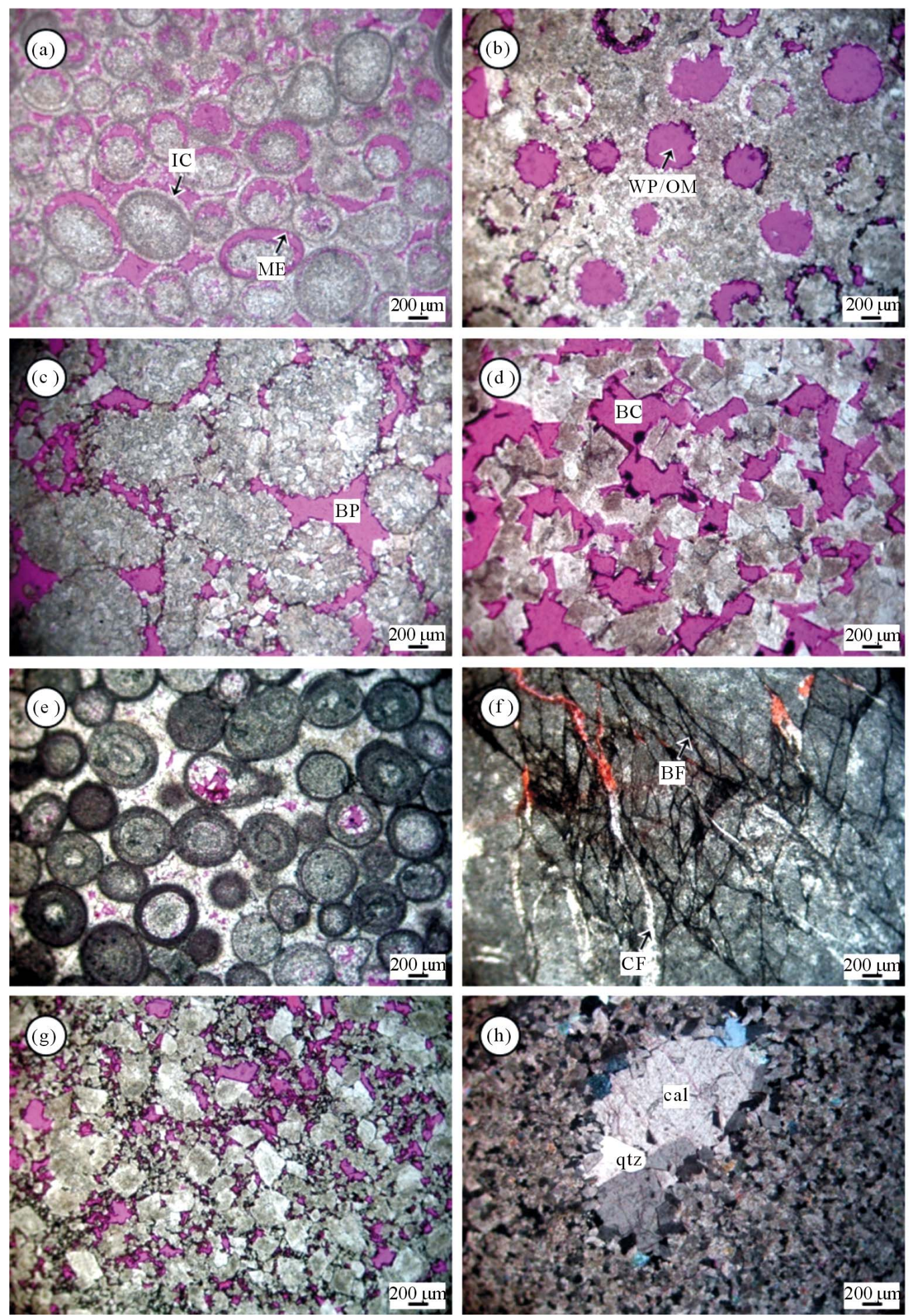

Figure 5. Main diagenetic aspects of dolomites of the Feixianguan reservoir in thin section photomicrographs in the Puguang Gas Field. (a) marine micrite envelopes (ME; dark color) and meteoric isopachous crusts (IC; bright color) on the surfaces of ooids; (b) intragranular (WP) or oomoldic (OM) pores interpreted by meteoric dissolution; (c) nonmimetic dolomitization of oolite limestone, with preserved intergranular pores (BP); (d) recrystallization of dolomite, forming intercrystalline pores (BC); (e) equant cements between ooids mainly formed during burial stage; (f) postdating-dolomitization fractures filled by calcite (CF) and bitumen (BF) successively; (g) bitumen cements decreased intercrystalline pores; (h) late calcite cements by thermochemical sulfate reduction and quartz (qtz) cements filled the pore space. All photos are taken under plane-polarized light except for $H$ which is taken under cross-polarized light. 
1) Pyrobitumen is present in the intercrystal vuggy pores of nearly all the dolomites with different crystal size (from micritic, fine, coarse, to sucrosic), which shows that most of the dolomites formed prior to the hydrocarbon emplacement (Figure 5(g)).

2) Coarse dolomite cements developed in vugs or carvens. However, few oil inclusions are found in these cements, while oil impregnation and pyrobitumen coating are common, which reconfirms that dolomite formation, as well as dolomite recrystallization, predated oil accumulation.

3) The main features of physical or mechanical compaction and chemical compaction (also pressure solution) include dewatering and deformation or reorientation of grains, stylolites or solution seams [6]. Stylolites and seams are common in limestones while scarce in dolomites in NE Sichuan (Figure 6). Few stylolites and no intergranular microstylolites could be found in the oolitic dolomite. Moreover, individual ooid shows little deformation. Therefore, it can be deduced that dolomitization predated stylolite formation and dolomite as the rock framework resisted intensive physical and chemical compaction.

Generally, incipient stylolitization may start at a burial depth of about $500 \mathrm{~m}$ (1640 ft.), and become intense below $830 \mathrm{~m}(2723 \mathrm{ft}$.) [21]. Consequently, dolomites may have been formed before they were buried to $500-800 \mathrm{~m}$ (1640 - $2625 \mathrm{ft}$.).
4) Oomoldic pores with geopetal structure in the oolitic dolomite formed during early meteoric dissolution prior to dolomite formation. Otherwise, dolomitization should have stabilized the aragonite or calcite grains to dolomite, which would not be leached fabric-selectively by meteoric water.

In conclusion, oolitic dolomite should have been formed at a shallow burial depth $(<500-800 \mathrm{~m}$, or 1640 $2625 \mathrm{ft}$.) postdating meteoric diagenesis and predating intensive compaction. However, dolomite may be recrystallized due to increasing burial depth to about 2000 $\mathrm{m}$ (6562 ft.) before petroleum charge.

After dolomitization, fractures occurred to greatly increase the reservoir permeability. Some of the fractures acted as the passageways of hydrocarbon-related fluids (Figure 5(f)).

More and more evidences have shown that dolomitization may directly or indirectly influence the reservoir porosity ([22] and references therein). It may directly cause: 1) dissolution by dolomitizing fluids which may be of little significance on pore formation; 2) mole-mole replacement of $\mathrm{Ca}^{2+}$ by $\mathrm{Mg}^{2+}$ which constructs porosity; 3) over dolomitization by excess fluids which destructs porosity; 4) volume-volume replacement of calcite or aragonite by dolomite which has no influence on total porosity; and 5) improvement of permeability nearly in all cases. The indirect influences are caused by the different mineral components and rock textures between
Well YB2

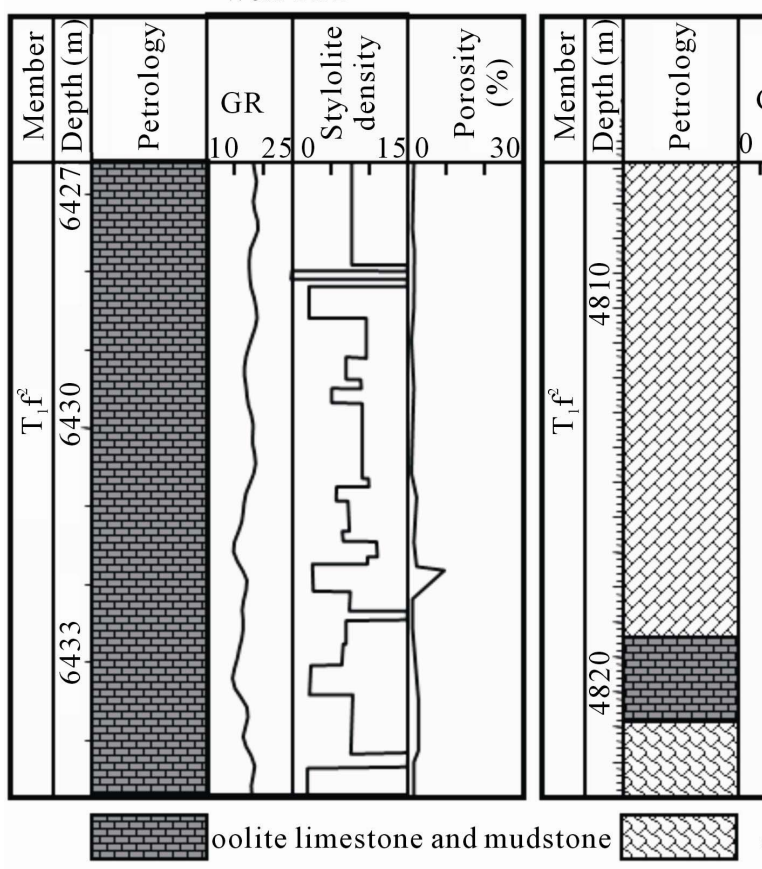

Well DW2

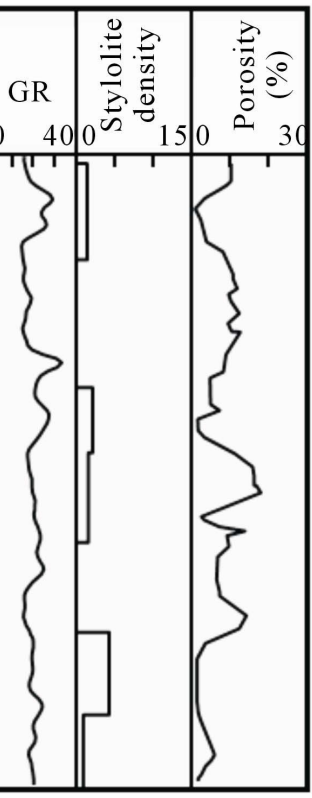

dolomitic limestone

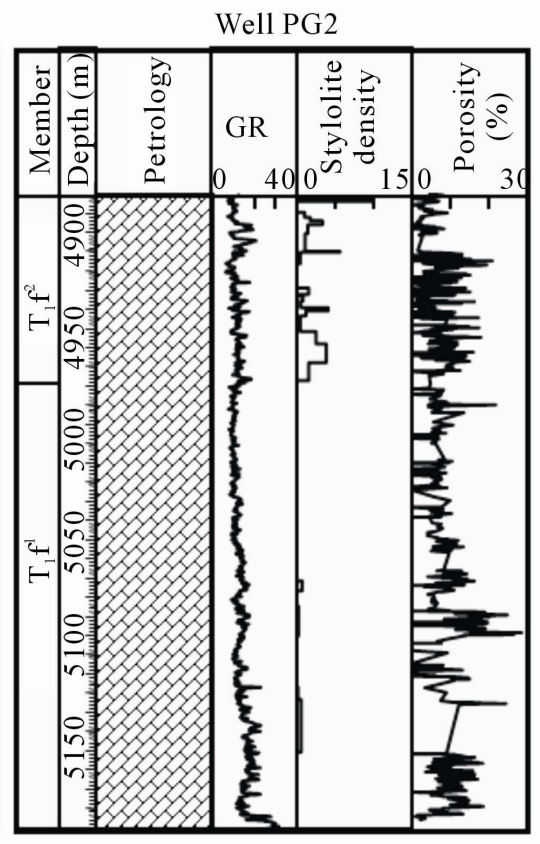

oolitic and crystalline dolomite

Figure 6. Counted stylolite densities in typical reservoir sections with different dolomitization intensities in the Feixianguan Formation of three wells, which shows that chemical compaction is intense in oolitic and crystalline limestones, while weak in dolomites. Well locations are shown in Figure 1. 
dolomites and the precursors. After dolomitization, the remaining calcite minerals are prone to be selectively dissolved; while the rocks become incompatible and fissile as well. In this area, pores are mainly developed in dolomites. Consequently, dolomitization is considered as a main constructive factor for the reservoir formation. Most of the intercrystalline porosities were created by dolomitization and recrystallization and can be quantified by Adobe Photoshop Analysis. As evidence, dolomite crystal sizes are positively correlated to the intercrystalline porosities (Figure 7).

Generally, both mechanical and chemical compactions are destructive to reservoir porosity $[16,23]$. However, to quantify the porosity loss caused by compaction is difficult, even impossible. Great attempts have been made by Heydari (2000) [16] and the citations therein. Through point counting, Heydari (2000) draw the conclusion that out of an original $40 \%$ porosity, $12.8 \%, 14.7 \%$, and $12.5 \%$ were destroyed by mechanical compaction, intergranular pressure solution (IPS), and related cementation, respectively [16]. No IPS, relatively weak physical and chemical dissolution have been found in the Feixianguan oolitic dolomites; while compaction is much more intense in crystalline dolomites and especially in limestones (Figure 6). The porosity loss by compaction is qualitatively estimated based on the density of stylolite, the content of grains and many previous studies [16,23].

\section{Stage 3: Oil Window Diagenesis}

In the late Indosinian Orogeny to the early Yanshanian Orogeny, the Lower Silurian source rocks entered oil window [3]. Organic acids were firstly expelled and may have partially dissolved the oolitic rocks and improved the reservoir quality [12]. Oil charge followed. In Well PG2, the earliest oil migration occurred at about $198 \mathrm{Ma}$ with burial depth at $\sim 2800 \mathrm{~m}$ (9186 ft.) according to the reconstructed structural configurations and burial history of the strata over geological time $[3,4]$. The paleo-oil field formed and was preserved for a long time until oil cracked $[2,3]$.

An important reaction, namely, liquid-hydrocarboninvolved thermochemical sulfate reduction (TSR) [4], should be noticed in this stage. Little evidence has been proposed for this reaction. However, sulfur-rich pyrobitumen and elemental sulfur in the reservoirs may indicate that liquid hydrocarbon did react with sulfate but little $\mathrm{H}_{2} \mathrm{~S}$ gas was formed during this stage of reaction [4].

\section{Stage 4: Gas Window Diagenesis}

In the middle and late episodes of the Yanshan orogeny, hydrocarbon source rocks entered into gas window for persistent subsidence and deep burial. Gases were injected into the reservoir to form a giant gas pool. At the same time, in-reservoir thermal maturation happened to the early charged oil [3]. The petroleum fluids in the paleo-oil field were altered by thermal cracking and thermochemical sulfate reduction (heavy-hydrocarbon dominated to methane dominated stages [4]) due to increasing burial depth and temperature. Abundant sulfur-rich pyrobitumens (Figure 5(g)), very dry gases with varying $\mathrm{H}_{2} \mathrm{~S}$ and nonhydrocarbon gas contents, and cements like elemental sulfur and calcite (Figure 5(h)) were the combined results [4]. During the thermochemical sulfate reduction, the reservoir pore structures may have been modified and porosity perhaps increased [3].

During the Himalayan orogeny, the gas trap was readjusted to present configuration. Thermochemical sulfate reduction might be terminated because of the decreased burial depth and temperature caused by uplift and denudation [3].

Thermochemical sulfate reduction has largely altered the fluids and gases within the Feixianguan reservoir [4];
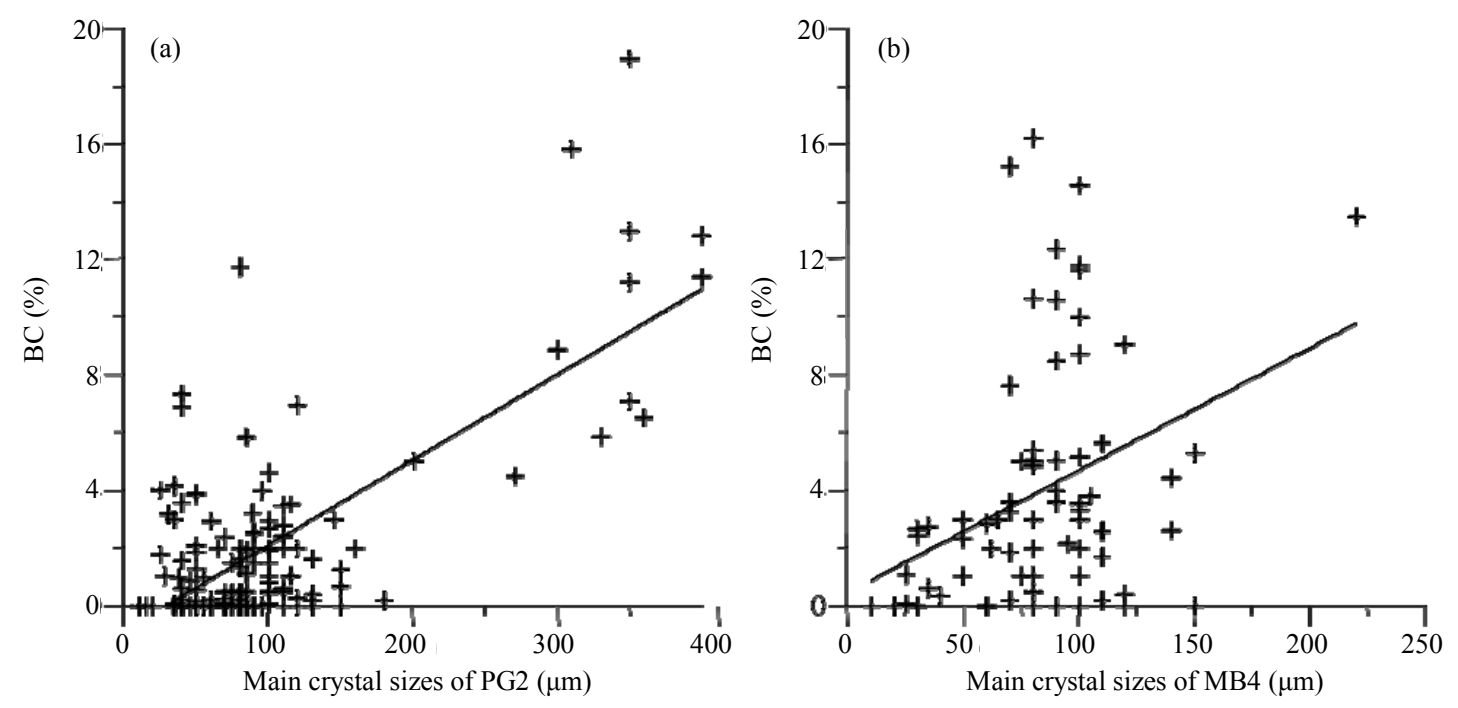

Figure 7. Dolomite crystal sizes vs. BC porosities showing positive correlation. 
while porosity variation during this process is controversial. Many previous studies may emphasize the importance of thermochemical sulfate reduction-related dissolution [24-29]. However, this view-point was doubted because wells with little $\mathrm{H}_{2} \mathrm{~S}$ gas indicating weak thermochemical sulfate reduction were drilled [30]. This research provides several pieces of evidences which show that thermochemical sulfate reduction negligibly influenced the total porosity despite local minor dissolution and contemporaneously local cementation by sulfur and calcite happened.

1) Most (about 2/3) of the pores in the Feixianguan reservoirs of Well PG2 and Well MB4 are fabric-selective. Thermochemical sulfate reduction is a deep burial reaction postdating oil accumulation. Minerals are supposed to have been stabilized and should not be selectively dissolved. Consequently, pores formed by thermochemical sulfate reduction are relatively less important in the study area.

2) Generally, pores are partly cemented by dolomite on the inner wall. Most of these dolomite cements are euhedral without signs of later dissolution.

3) Most of the pores are rimmed by bitumen, which means that these pores are generated before oil emplacement and paleo-oil field formation.

4) The dissolution always co-exists with the cementation by thermochemical sulfate reduction byproducts. Porosity is probably produced from the dissolution of calcium sulfate to yield $\mathrm{SO}_{4}^{2-}$, the generation of $\mathrm{CO}_{2}$, and the precipitation of metal sulfide; while lost due to the precipitation of authigenic carbonates, elemental sulfur and/or sulfides [31]. Microscopic observation and Adobe Photoshop Analysis on the Well PG2 have shown that pores possibly created by thermochemical sulfate reduction dissolution are always less than or equals to those excluded by elemental sulfur and calcite precipitated during thermochemical sulfate reduction. Consequently, the total porosity may stay unchanged or slightly decreased during this reaction.

In this diagenetic stage, small amounts of quartz cemented in some pores (Figure 5(h)). And fracturing occurred as the latest diagenesis which has little impact on the total porosity.

\subsection{Diagenetic Heterogeneity}

Diagenetic features and intensity are heterogeneous in different regions of NE Sichuan Basin or even in different reservoir sections of the same well core.

The Feixianguan Formation was deposited at the similar facies in the Well PG2 and in the neighbor Well MB4 and experienced similar paragenetic sequence. However, oolitic dolomite with abundant oomoldic/intragranular and intercrystalline pores developed in the Well PG2
(Figures 3A and 5(b)), while oolitic dolomite of the Well MB4 has abundant vugs, intergranular and intercrystaline pores (Figures 3B and 5(c)). At the near-surface stage, the Feixianguan Formation of the Well PG2 experienced intense meteoric dissolution and abundant oomoldic/ intragranular pores formed (Figure 5(b)). The meteoric dissolution would be macroscale dissolution caused by large water flux and water strongly undersaturated with respect to aragonite [15]. Porosity, as well as permeability, was then greatly intensified by dolomitization, recrystallization and organic dissolution. After oil emplacement and pyrobitumen cementation, few pores were created. In the contrary, pyrobitumen, elemental sulfur, calcite and minor quartz cements filled part of the pore space.

Even though the Feixianguan Formation of the Well MB4 was similarly exposed as did in the Well PG2, early meteoric diagenesis may have exerted different impacts on the reservoir sections of the Well MB4. The meteoric or fresh-marine-mixed water would be slightly undersaturated with respect to aragonite and the water flux was slow, aragonite grains may be stabilized and proceed by microscale dissolution or replacement rather than be dissolved [15]. Consequently, oomoldic or intragranular pores are scarce, while original intergranular pores are well preserved in the Well MB4 (Figures 3A and 5(c)). Following the meteoric diagenesis, dolomitization and recrystallization formed the intercrystalline pores and greatly increased the permeability. Porosity slightly decreased after oil emplacement because of the pyrobitumen, sulfur, calcite and quartz cementation.

Dolomitization may be a pre-requisite to form an effective reservoir of the Feixianguan Formation in the NE Sichuan, which is proved by the Well YB2 from the opposite angle. The Feixianguan oolites in this well are not dolomitized. The present porosities are mainly less than $3 \%$ (Figure 6). Although early meteoric water dissolved some ooid grains, these oomolds were filled by burial cements. Due to the weak meteoric dissolution and the absence of dolomitization, most of the original and secondary pores were excluded by mechanical compaction, pressure solution, and burial cementation.

\subsection{Porosity Evolution}

To recover the porosity evolution history, an estimation of original porosity value is required. Several previous studies have estimated theoretically or experimentally the original porosity value of grainstones which is controlled by sorting and grain packing arrangement ([16] and citations therein). An original porosity of $40 \%$ was assumed for the Smackover ooid grainstones by Heydari (2000) [16]. In the Well PG2, oolites have an average grain content of about $66 \%$, among which oolite with the best-preserved original texture and the least compaction 
(Well PG2, $5030.5 \mathrm{~m}$ or $16,504 \mathrm{ft}$.) has $60.6 \%$ of grain contents. Therefore, a $40 \%$ of original porosity seems reasonable for the Feixianguan oolites in NE Sichuan.

On the basis of the paragenetic sequence (Figure 4) and the analyses of the influences of diageneses on reservoir porosity, porosity evolution history could be (semi-)quantitatively evaluated. The recovered curves start from the present porosity $\left(\mathrm{P}_{\mathrm{p}}\right)$ quantified by Adobe Photoshop Analysis. As the latest diagenesis is late fracturing which neatly increased porosity, the porosity before late fracturing $\left(\mathrm{P}_{\mathrm{p} 1}\right)$ should be calculated as $\mathrm{P}_{\mathrm{p}}$ minus porosity created by late fracturing. And the porosity before quartz cementation $\left(\mathrm{P}_{\mathrm{p} 2}\right)$ should be computed as $\mathrm{P}_{\mathrm{p} 1}$ plus quartz contents. The $\mathrm{P}_{\mathrm{p} 2}$ plus thermochemical sulfate reduction cements (elemental sulfur and calcite) and minus porosities generated by thermochemical sulfate reduction dissolution equals to the porosity before thermochemical sulfate reduction $\left(\mathrm{P}_{\mathrm{p} 3}\right)$. The $\mathrm{P}_{\mathrm{p} 3}$ added by bitumen contents is considered as the porosity when oil charged $\left(\mathrm{P}_{\mathrm{p} 4}\right)$. Since the contribution of organic dissolution is hard to determine, the pre-bitumen porosity evolution could only be semi-quantitatively recovered started from the original porosity $\left(\mathrm{P}_{\mathrm{o}}\right)$. The $\mathrm{P}_{\mathrm{o}}$ subtracts marine cements to get the porosity after marine cementation $\left(\mathrm{P}_{\mathrm{o} 1}\right)$. The $\mathrm{P}_{\mathrm{o} 1}$ will be increased to $\mathrm{P}_{02}$ after meteoric dissolution and cementation, therefore, $\mathrm{P}_{\mathrm{o} 2}$ equals to $\mathrm{P}_{\mathrm{o} 1}$ plus meteoric intragranular, breccia, carven and dissolutionenlarged porosities. Porosity after dolomitization and recrystallization $\left(\mathrm{P}_{03}\right)$ should be calculated as $\mathrm{P}_{02}$ plus intercrystalline porosity. As stated above, the porosity loss due to compaction and increase by organic dissolution are estimated through the relative intensity of these diageneses in different reservoirs. During early diagenetic stage before intense chemical compaction, the total porosities may have been largely preserved in spite of the modification of pore systems [32].

The historical porosities are set in the time coordinate axis. Connect the dots representing the porosity values and the porosity evolution curves are obtained. Typical reservoir sections of the Well PG2 and the Well MB4 are studied and a comparing curve of the Well YB2 is also shown in Figure 8.

\subsection{Implication for Further Exploration}

Zhao et al. [27], Yang et al. [33] and Ma et al. [34] have pointed out some key factors controlling the formation of the Feixianguan reservoirs including depositional facies, early meteoric dissolution, dolomitization, organic acids dissolution, burial dissolution and thermochemical sulfate reduction-related dissolution. And Xia et al. [30] provided some evidences against deep burial dissolution, especially the dissolution related to thermochemical sulfate reduction. Nevertheless, the main controlling fac- tor(s) is (are) still controversial, which greatly restricted further exploration of the Feixianguan reservoirs in other regions in the NE Sichuan Basin.

Through this research, paragenetic sequence and porosity evolution history of the Feixianguan reservoirs in the Puguang area are recovered, which clearly shows that the reservoir formation was mainly controlled by early meteoric dissolution, dolomitization, and organic acids dissolution other than deep burial dissolution. In general, the more pores were created before oil accumulation; the higher porosities are obtained at present. Porosities formed during relatively early diagenetic stages must be effectively preserved hence make great contribution to the present reservoir spaces. Consequently, the preservation mechanisms of the reservoir porosities may be of great significance to the formation of effective reservoirs in the NE Sichuan Basin. These preservation factors roughly proposed by this research may include early meteoric cementation, dolomitization, thick evaporates as cap rocks leading to a closed diagenetic environments, early hydrocarbon emplacement and paleo-oil pool formation, overpressure through oil-gas cracking, etc.

\section{Conclusions}

Several conclusions can be drawn through this research:

1) Diagenetic phases can be divided into near-surface (including marine and meteoric environment), pre-oil window, oil window, and gas window stages for the Feixianguan reservoirs, Puguang Gas Field, NE Sichuan Basin.

2) The main diagenetic processes affecting the Feixianguan reservoir units include: a) marine cementation; b) meteoric dissolution and cementation; c) early dolomitization and dolomite recrystallization; d) mechanical and chemical compaction; e) burial cementation; f) early fracturing; g) organic dissolution and hydrocarbon evolution; h) thermochemical sulfate reduction dissolution and cementation by pyrite, sulfur and calcite; and i) minor late fracturing. The porosity increase or loss by most of the diageneses can be quantified by the Adobe Photoshop Analysis method.

3) On the basis of the paragenetic sequence and the quantification of the influences of diageneses on reservoir porosity, porosity evolution curve could be quantitatively recovered.

4) The Feixianguan reservoirs were formed mainly by early meteoric dissolution, dolomitization, and organic acids dissolution other than deep burial dissolution. And the preservation mechanisms of the early-formed reservoir porosities may be of great significance to the further exploration of the deep buried Feixianguan reservoirs in the NE Sichuan Basin. 


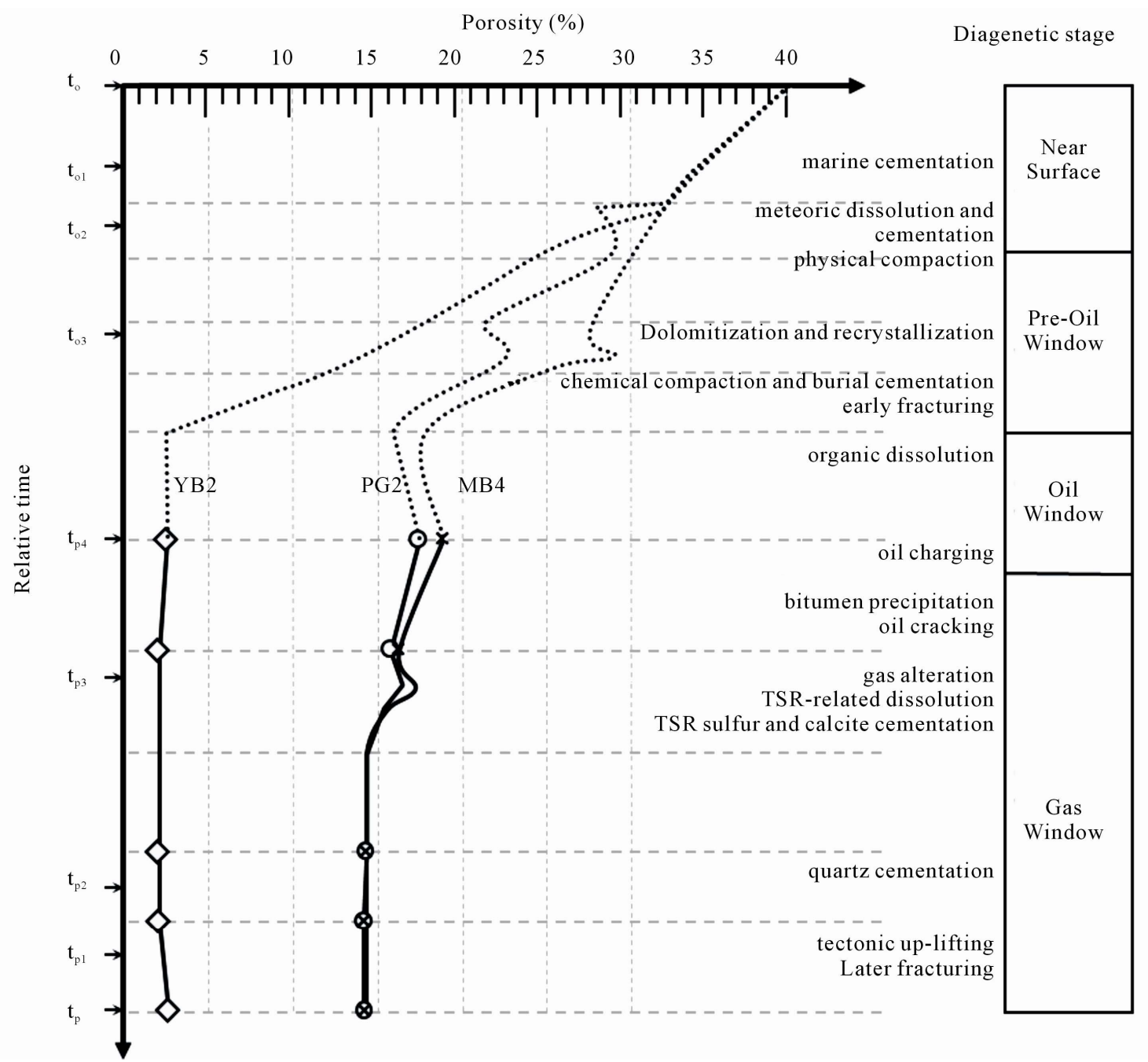

Figure 8. Typical porosity evolution curves of the Feixianguan oolitic dolomites with abundant WP pores of Well PG2, with plenty BP pores of Well MB4 and non-reservoir oolitic limestone of Well YB2. Diagenetic stages and diageneses are also shown. $P_{0}$ is the original porosity at time to, and $P_{p}$ the present porosity at time tp. $P o 1$ is the porosity after marine cementation, $P_{02}$ the porosity after meteoric dissolution and cementation, $P_{03}$ the porosity after dolomitization and recrystallization, $P p 1$ the porosity before later fracturing, $P_{p 2}$ the porosity before quartz cementation, $P_{p 3}$ the porosity before thermochemical sulfate reduction, $P_{\mathrm{p} 4}$ the porosity before bitumen cementation and also the porosity when oil charged. The dotted lines are qualitatively estimated as stated in the text.

\section{Acknowledgements}

This study was jointly funded by the National Science and Technology Major Project (2011ZX05005-003-010 HZ), the National Natural Science Foundations of China (41002029 and 41272137) and the project from Southern Exploration and Development Company (SEDC) of SINOPEC. The authors are indebted to Prof. Ma Yongsheng with SINOPEC. We appreciate the support on sampling from the Southern Exploration and Development Company (SEDC) of SINOPEC. David E. Eby, Matthias Grobe, R. P. Major, Stephen C. Ruppel, Stephen E. Laubach and an anonymous reviewer are thanked for their thoughtful comments and the polish of the language.

\section{REFERENCES}

[1] S. N. Ehrenberg, P. H. Nadeau and O. Steen, "Petroleum Reservoir Porosity versus Depth: Influence of Geological Age," AAPG Bulletin, Vol. 93, No. 10, 2009, pp. 12811296. doi: $10.1306 / 06120908163$

[2] Y. S. Ma, X. S. Guo, T. L. Guo, R. Huang, X. Y. Cai, et al., "The Puguang Gas Field: New Giant Discovery in the Mature Sichuan Basin, Southwest China," AAPG Bulletin, Vol. 91, No. 5, 2007, pp. 627-643. doi:10.1306/11030606062

[3] Y. S. Ma, S. C. Zhang, T. L. Guo, G. Y. Zhu, X. Y. Cai, et al., "Petroleum Geology of the Puguang Sour Gas Field in the Sichuan Basin, SW China," Marine and Petroleum Geology, Vol. 25, No. 4-5, 2008, pp. 357-370. doi:10.1016/j.marpetgeo.2008.01.010 
[4] F. Hao, T. L. Guo, Y. M. Zhu, X. Y. Cai, H. Y. Zou, et al., "Evidence for Multiple Stages of Oil Cracking and Thermochemical Sulfate Reduction in the Puguang Gas Field, Sichuan Basin, China," AAPG Bulletin, Vol. 92, No. 5, 2008, pp. 611-637. doi:10.1306/01210807090

[5] X. F. Zhang, Z. X. Cai, W. X. Hu and L. Li, "Using Adobe Photoshop to Quantify Rock Textures," Acta Sedimentologica Sinica, Vol. 27, No. 3, 2009, pp. 7-13.

[6] P. A. Scholle and D. S. Ulmer-Scholle, "A Color Guide to the Petrography of Carbonate Rocks: Grains, Textures, Porosity, Diagenesis," AAPG Memoir, Vol. 77, 2003, pp. $1-477$.

[7] L. Van der Plas and A. C. Tobi, "A Chart for Judging the Reliability of Point Counting Results," American Journal of Science, Vol. 263, No. 1, 1965, pp. 87-90. doi:10.2475/ajs.263.1.87

[8] R. T. Patterson and E. Fishbein, "Re-examination of the Statistical Method Used to Determine the Number of Point counts Needed for Micropaleontological Quantitative Research," Journal of Paleontology, Vol. 63, No. 2, 1989, pp. 245-248.

[9] J. V. White, B. L. Kirkland and J. P. Gournay, "Quantitative Porosity Determination of Thin Sections Using Digitized Images," Research Methods Papers, 1998, pp. 220221.

[10] S. Nishimoto, "Modal Analysis of Granitic Rocks by a Personal Computer Using Image Processing Software 'Adobe Photoshop TM',' Ganko, Vol. 91, No. 6, 1996, pp. 235-241.

[11] M. J. Morse and J. R. Boles, "Can Adobe Photoshop be Used to Quantify Sandstone Porosity?" AAPG Bulletin, Vol. 82, No. 5A, 1998, pp. 854.

[12] P. W. Choquette and L. C. Pray, "Geologic Nomenclature and Classification of Porosity in Sedimentary Carbonates," AAPG Bulletin, Vol. 54, No. 2, 1970, pp. 207-250.

[13] E. Heydari, "The Role of Burial Diagenesis in Hydrocarbon Destruction and $\mathrm{H}_{2} \mathrm{~S}$ Accumulation, Upper Jurassic Smackover Formation, Black Creek Field, Mississippi," AAPG Bulletin, Vol. 81, No. 1, 1997, pp. 26-45.

[14] M. M. Savard, B. Beauchamp and J. Veizer, "Significance of Aragonite Cements around Cretaceous Marine Methane Seeps," Journal of Sedimentary Research, Vol. 66, No. 3, 1996, pp. 430-438.

[15] N. P. James and P. W. Choquette, "Diagenesis 9. Limestones-The Meteoric Diagenetic Environment," Geoscience Canada, Vol. 11, No. 4, 1984, pp. 161-194.

[16] E. Heydari, "Porosity Loss, Fluid Flow, and Mass Transfer in Limestone Reservoirs: Application to the Upper Jurassic Smackover Formation, Mississippi," AAPG Bulletin, Vol. 84, No. 1, 2000, pp. 100-118.

[17] L. P. Su, P. Luo, S. R. Hu, Z. Luo, L. H. Liu, et al., "Diagensis of Oolitic Bank of the Feixianguan Formation of Lower Triassic in Luojiazhai Gas Field, Northeastern Sichuan Province," Journal of Palaeogeography, Vol. 6, No. 2, 2004, pp. 182-190.

[18] H. Chen, J. C. Tian, X. Zhang, Y. Yang and G. Fu, "Dolomitization Genetic of the Lower Triassic Feixianguan Group Oolitic Beach in Northeast Sichuan Basin," Natu- ral Gas Industry, Vol. 28, No. 1, 2008, pp. 42-46.

[19] S. J. Huang, H. R. Qing, C. R. Pei, Z. W. Hu, S. J. Wu, et al., "Strontium Concentration, Isotope Composition and Dolomitization Fluids in the Feixianguan Formation of Triassic, Eastern Sichuan of China," Acta Petrologica Sinica, Vol. 22, No. 8, 2006, pp. 2123-2132.

[20] M. S. Gao, R. C. Zheng, H. G. Wen, L. X. Li and H. Li, "Lithological Characteristics of Dolomite in the Lower Triassic Feixianguan Formation of the NE Sichuan Basin, China," Journal of Chengdu University of Technology (Science \& Technology Edition), Vol. 34, No. 3, 2007, pp. 297-304.

[21] J. Lonnee and H. G. Machel, "Pervasive Dolomitization with Subsequent Hydrothermal Alteration in the Clarke Lake Gas Field, Middle Devonian Slave Point Formation, British Columbia, Canada," AAPG Bulletin, Vol. 90, No. 11, 2006, pp. 1739-1761. doi:10.1306/03060605069

[22] X. F. Zhang, B. Liu, Z. X. Cai and W. X. Hu, "Dolomitization and Carbonate Reservoir Formation," Geolotical Science and Technology Information, Vol. 29, No. 3, 2010, pp. 79-85.

[23] J. W. Schmoker and R. B. Halley, "Carbonate Porosity versus Depth: A Predictable Relation for South Florida," AAPG Bulletin, Vol. 66, No. 12, 1982, pp. 2561-2570.

[24] Y. G. Wang, L. R. Dou, Y. C. Wen, J. Zhang and H. Y. Liu, "Origin of $\mathrm{H}_{2} \mathrm{~S}$ in Triassic Feixianguan Formation Gas Pools, Northeastern Sichuan Basin, China," Geochimica, Vol. 31, No. 6, 2002, pp. 517-524.

[25] G. Y. Zhu, S. C. Zhang, Y. B. Liang, Y. S. Ma, J. X. Dai, et al., "Dissolution and Alteration of the Deep Carbonate Reservoirs by Thermochemical Sulfate Reduction: An Important Type of Deep-buried High-quality Carbonate Reservoirs in Sichuan Basin," Acta Petrologica Sinica, Vol. 22, No. 8, 2006, pp. 2182-2194.

[26] G. Y. Zhu, S. C. Zhang and Y. S. Ma, "Effectiveness of Thermochemical Sulfate Reduction on Oil and Gas Industry- $\mathrm{A} \mathrm{H}_{2} \mathrm{~S}$ Formation Accelerating Development of the Secondary Pores in Reservoirs," Earth Science Frontiers, Vol. 13, No. 3, 2006, pp. 141-149.

[27] W. Z. Zhao, Z. C. Wang and Y. G. Wang, "Formation Mechanism of Highly Effective Gas Pools in the Feixianguan Formation in the NE Sichuan Basin," Geological Review, Vol. 52, No. 5, 2006, pp. 708-718.

[28] Y. S. Ma, T. L. Guo, G. Y. Zhu, X. Y. Cai and Z. Y. Xie, "Simulated Experiment Evidences of the Corrosion and Reform Actions of $\mathrm{H}_{2} \mathrm{~S}$ to Carbonate Reservoirs: an Example of Feixianguan Formation, East Sichuan," Chinese Science Bulletin, Vol. 52, Suppl. 1, 2007, pp. 178-183. doi:10.1007/s11434-007-6019-3

[29] D. M. Zeng, X. Z. Wang and S. Y. Wang, "The Significance of Dissolution in the Development and Evolution of Reservoir in Feixianguan Formation in the Northeast Sichuan Basin," Journal of Southwest Petroleum University, Vol. 29, No. 1, 2007, pp. 15-18.

[30] M. J. Xia, R. J. Deng, Y. W. Jiang, J. X. Bi, X. J. Jin, et al., "Exposition on Material Base and Preservation Causes of Oolitic Beach Reservoir in Puguang Gas Field," Fault-Bolck Oil \& Gas Field, Vol. 16, No. 6, 2009, pp. 5-9. 
[31] H. G. Machel, "Bacterial and Thermochemical Sulfate Reduction in Diagenetic Settings-Old and New Insights," Sedimentary Geology, Vol. 140, No. 1-2, 2001, pp. 143-175.doi:10.1016/S0037-0738(00)00176-7

[32] R. G. Maliva, T. M. Missimer, E. A. Clayton and J. A. D. Dickson, "Diagenesis and Porosity Preservation in Eocene Microporous Limestones, South Florida, USA," Sedimentary Geology, Vol. 217, No. 1-4, 2009, pp. 85-94. doi:10.1016/j.sedgeo.2009.03.011

[33] W. Yang, G. Q. Wei, H. Jin., L. Zhang and J. H. Shen, et al., "Diagenesis and Pore Evolution of the Oolitic Shoal Reservoir in the Feixianguan Formation in Northeastern Sichuan," Geology in China, Vol. 34, No. 5, 2007, pp. 822-828.

[34] Y. S. Ma, T. L. Guo, X. F. Zhao and X. Y. Cai, "The Formation Mechanism of High-quality Dolomite Reservoir in the Deep of Puguang Gas Field," Science in China Series D: Earth Sciences, Vol. 51, Suppl. 1 2008, pp. 53-64. doi:10.1007/s11430-008-5008-y 